\title{
Cardiovascular Responses During Downhill Treadmill Walking at Self-Selected Intensity in Older Adults
}

\author{
Mandy L. Gault, Richard E. Clements, and Mark E.T. Willems
}

\begin{abstract}
Cardiovascular responses of older adults to downhill (DTW, $-10 \%$ incline) and level treadmill walking $(0 \%)$ at self-selected walking speed (SSWS) were examined. Fifteen participants (age $68 \pm 4 \mathrm{yr}$, height $1.69 \pm 0.08 \mathrm{~m}$, body mass $74.7 \pm 8.1 \mathrm{~kg}$ ) completed two 15 -min walks at their SSWS $(4.6 \pm 0.6 \mathrm{~km} / \mathrm{hr})$. Cardiovascular responses were estimated using an arterial-volume finger clamp and infrared plethysmography. Oxygen consumption was $25 \%$ lower during DTW and associated with lower values for stroke volume $(9.9 \mathrm{ml} / \mathrm{beat})$, cardiac output $(1.0 \mathrm{~L} / \mathrm{min})$, arteriovenous oxygen difference $\left(a-v \mathrm{O}_{2}\right.$ diff, $\left.2.4 \mathrm{ml} / \mathrm{L}\right)$, and systolic blood pressure $(10 \mathrm{mmHg})$, with no differences in heart rate or diastolic and mean arterial blood pressure. Total peripheral resistance (TPR) was higher $(2.11 \mathrm{mmHg}$ ) during DTW. During downhill walking, an exercise performed with reduced cardiac strain, endothelial changes, and reduced metabolic demand may be responsible for the different responses in TPR and $a-v \mathrm{O}_{2}$ diff. Future work is warranted on whether downhill walking is suitable for higher risk populations.
\end{abstract}

Keywords: eccentric exercise, cardiovascular physiology, aging, health

Regular exercise in older adults provides health benefits (American College of Sports Medicine, 2009). Exercise that includes eccentric contractions of skeletal muscles has recently attracted attention, as it may be more suitable for older individuals with reduced exercise tolerance and patients with chronic health conditions (Roig, Shadgan, \& Reid, 2008). During movements with eccentric contractions, the skeletal muscles perform negative work. Such movements are common during recreational and daily activities.

Downhill treadmill walking exemplifies a whole-body exercise involving eccentric contractions of lower limb musculature. Only a few studies have reported differences in the acute physiological responses that occur during downhill treadmill walking compared with level and uphill treadmill walking (Navalta, Sedlock, \& Park, 2004; Pivarnik \& Sherman, 1990). Acute physiological responses that occur in response to exercise at different gradients are causally linked with concomitant changes in the potential energy state of the human body. As a result, exercise

The authors are with the Dept. of Sport and Exercise Sciences, University of Chichester, Chichester, UK. 
conducted on different gradients requires different amounts of oxygen consumption (Wanta, Nagle, \& Webb, 1993); for example, oxygen consumption is reduced during downhill walking. A curvilinear response in oxygen consumption, independent of walking speed, was reported for young males walking at gradients of 0-18\% (Wanta et al., 1993). Similar observations were reported for older (64 \pm 3 years) men and women at gradients of $+5 \%$ to $-20 \%$ (Navalta et al., 2004).

The energy and oxygen costs of walking at different gradients are associated with concurrent adaptations in blood flow and blood pressure (Navalta et al., 2004; Robergs, Wagner, \& Skemp, 1997). Dynamic changes in blood flow and blood pressure during exercise are the two main variables that contribute to changes in the requirement for oxygen consumption (Bassett \& Howley, 2000) with associated changes in heart rate (HR), stroke volume (SV), and cardiac output (Q). In response to an increased oxygen demand, Q is normally increased through increases in both HR and SV, with changes in SV caused by the Frank-Starling mechanism (Smith \& Kampine, 1990). This results in an increased ejection fraction from approximately $60 \%$ at rest to $80 \%$ during submaximal exercise in healthy subjects (Goodman, Liu, \& Green, 2005). Increases in SV and ejection fraction during exercise cause an increase in systolic blood pressure (SBP; Berne \& Levy, 1981) and mean arterial pressure (MAP), resulting in a greater pulse pressure (Berne \& Levy, 1981; Overend, Versteegh, Thompson, Birmingham, \& Vandervoort, 2000). However, as stroke volume increases during exercise, total peripheral resistance (TPR) will decrease (Berne \& Levy, 1981; Hambrecht et al., 2000). This decreased TPR is the result of an increase in endothelium-dependent vasodilation of the skeletal muscle vasculature (Rothe, 1986). The additional physiological variable that relates to the required oxygen consumption is the arteriovenous oxygen difference ( $a-v \mathrm{O}_{2}$ diff) the oxygen difference between the arterial blood and mixed venous return indicating oxygen extracted by muscles (e.g., De Cort, Innes, Barstow, \& Guz, 1991). Rate pressure product (RPP) - the product of HR and SBP - is a further useful and practical parameter often used to provide a noninvasive predictor of myocardial oxygen consumption, that is, an index of cardiovascular strain (Hui, Jackson, \& Wier, 2000). Isometric exercise, in the form of clasping the hands together as tightly as possible, has been shown to increase RPP by $3 \%$ in comparison with resting values for normotensive individuals. Such a parameter is used to assess the risk of cardiovascular disease, with a high resting RPP indicative of a cardiovascular risk factor and a low RPP at peak exercise a further indication of heart disease (Hui et al., 2000; Mbada, Akinwande, Babalola, Seyi-Adeyemo, \& Odejide, 2007)

The cardiovascular responses to eccentric exercise have not been thoroughly investigated. It has been shown that HR increases to a greater extent when going from rest to concentric isokinetic exercise than from rest to eccentric isokinetic exercise (Overend et al., 2000). Other studies (Navalta et al., 2004; Pivarnik \& Sherman, 1990; Wanta et al., 1993) did not observe differences in HR response during level (concentric) and downhill (eccentric) treadmill walking, in conjunction with no observed differences in SBP. However, a detailed examination of the cardiovascular responses in relation to the reduced oxygen consumption during eccentric exercise in older adults at a self-selected intensity has not been conducted. Such data are required to clarify whether this novel mode of exercise may be of benefit for populations with a reduced exercise tolerance. 
Therefore, the aims of the current study were to examine the cardiovascular and physiological responses that occur in older adults during downhill and level treadmill walking. Such analysis will allow the identification of the cardiovascular mechanisms that underlie the reported differences in oxygen consumption between level and downhill treadmill walking at a self-selected walking speed. We hypothesized that downhill treadmill walking would elicit lower oxygen consumption than level treadmill walking, due to the combined effects of reduced $\mathrm{Q}$ and $a-v \mathrm{O}_{2}$ diff.

\section{Methods}

\section{Participants}

Fifteen independent older adults ( 8 men and 7 women; age $68 \pm 4$ years, height $1.69 \pm 0.08 \mathrm{~m}$, body weight $74.7 \pm 8.0 \mathrm{~kg}$, resting heart rate $69 \pm 7$ beats $/ \mathrm{min}$, blood pressure $137 / 83 \pm 5 / 9 \mathrm{mmHg}$, resting rate pressure product $10,055 \pm 1,225$ beats $\cdot \mathrm{min}^{-1} \cdot \mathrm{mmHg}^{-1}, \mathrm{VO}_{2 \max } 29.6 \pm 9.1 \mathrm{ml} \cdot \mathrm{kg}^{-1} \cdot \mathrm{min}^{-1}$ ) free from illness and disease volunteered to take part in the study. Current participants are in the 40-50th percentiles for their age group in maximal oxygen uptake $\left(\mathrm{VO}_{2 \max }\right)$. Although participants were free from cardiovascular disease, the resting RPP of over 10,000 indicated the group as a whole to be at an increased risk for cardiovascular disease. Some participants had previously experienced treadmill walking; none had any experience of walking on a treadmill at a negative gradient. Ethical approval for all procedures and protocols was provided by the ethics committee of the university. Participants completed a health questionnaire, provided written informed consent, and were free from any musculoskeletal injuries. They were instructed to refrain from any vigorous physical activity on the day before treadmill walking and to abstain from the consumption of caffeine, ergogenic drinks, and food for a 2-hr period before all the tests.

\section{Preliminary Measures}

Resting HR and blood pressure were measured using an automated sphygmomanometer (Omron 705 IT, Medisave, UK) after subjects had been seated for $20 \mathrm{~min}$. Height (Holtain Ltd., Crymych, UK) and body weight (Seca Model 880, Seca, UK) were then recorded. Participants completed the Rockport Fitness Walking Test to allow calculation of predicted $\mathrm{VO}_{2 \max }$ using the equation of Kline et al. (1987):

$$
\begin{gathered}
\mathrm{VO}_{2 \max }(\mathrm{L} / \mathrm{min})=6.9652+(0.0091 \times \text { weight })-(0.0257 \times \text { age }) \\
+(0.5955 \times \text { sex })-(0.2240 \times \mathrm{T})-(0.0115 \times \mathrm{HR})
\end{gathered}
$$

where weight $=$ pounds; age $=$ years; $\operatorname{sex}=$ female 0 , male $1 ; \mathrm{T}=$ time in minutes to 100ths of a minute taken at the completion of the 1-mile walk; and HR = heart rate determined at the completion of the walk. Although this predictive equation has a larger standard error of estimates $(0.325 \mathrm{~L} / \mathrm{min})$ than laboratory tests, if appropriate test administration is followed, as in the current study, results can be more reliable (Kline et al., 1987). For example, one could use one familiarization walk, monitoring HR and stride frequency to ensure that the same intensity was maintained throughout, and verbal encouragement for all individuals regarding their 
stride frequency (Gault, Clements, \& Willems, 2009). All participants completed two preliminary 15 -min sessions to become familiarized with treadmill walking (Wass, Taylor, \& Matsas, 2005). During these sessions, participants walked on the treadmill at a starting speed of $1.5 \mathrm{~km} / \mathrm{hr}$; this speed was then gradually increased to a comfortable walking speed. After familiarization, self-selected walking speed (SSWS) was determined by the participants walking at $2.5 \mathrm{~km} / \mathrm{hr}$ with increments of $0.2 \mathrm{~km} / \mathrm{hr}$ every $30 \mathrm{~s}$ until they felt that they would not be able to maintain the next speed for $30 \mathrm{~min}$. This speed was then maintained for $15 \mathrm{~min}$ and confirmed to be the participant's SSWS. Average walking speed was $4.6 \pm 0.6 \mathrm{~km} / \mathrm{hr}$. Participants were also familiarized during the initial sessions with wearing the Douglas bag mouthpiece and two-way valve, as well as the Portapres system.

\section{Experimental Design and Protocol}

The study was a two-way crossover design. Each subject performed the following two conditions on a motorized treadmill (Woodway Ergo ELG 70, Cranlea \& Co., Birmingham, UK, or a HP Cosmos Pulsar, Bodycare Products, Southam, UK): Walking Condition 1, 15 min of walking at the SSWS on a $0 \%$ gradient (LTW); Walking Condition 2, 15 min at the SSWS on a $-10 \%$ gradient (DTW). Both walking conditions were completed on the same treadmill. The cardiovascular responses were recorded during each 15-min bout on a beat-to-beat basis. Expired air was collected in the last 3 min of each walk.

\section{Cardiovascular Measurements}

Cardiovascular measures were taken using the Portapres Model 2 (Finapres Medical Systems BV, Amsterdam, The Netherlands), a beat-to-beat finger pressure analyzer that allows the noninvasive continuous measurement of blood pressure (Eckert \& Horstkotte, 2002; Wesseling, de Wit, Settels, \& Klawer, 1992). A number of studies have shown this method to be an acceptable alternative to invasive blood pressure monitoring at rest and during low- to moderate-intensity exercise (Eckert \& Horstkotte, 2002; Parati, Casadei, Groppelli, Di Rienzo, \& Mancia, 1989). Although Q and SV tend to be overestimated at rest and during peak exercise, in comparison with a rebreathing technique, the mean values of both changed proportionately (Pitt, Marshall, Diesch, \& Hainsworth, 2004). In addition, Pitt et al. suggested that the Portapres may be useful in assessing changes in individual subjects, for example, during exercise. The Portapres Model 2 provides an indirect measurement of blood pressure in the finger based on the arterial-volume-clamp method of Peñáz (1973) and physical criteria for the proper unloading of the finger arteries (Wesseling et al., 1992). It consists of a main unit, a pump unit, and a battery compartment contained in a waistband and weighs a total of $2.2 \mathrm{~kg}$. An appropriate-size cuff was fitted around the middle phalanx of the middle finger of the left hand, making sure there was no bladder overlap. Subjects remained seated with their hand supported across their chest after the placement of the cuff. This position was maintained to allow the recording of a minimum of 30 heartbeats continuously in line with the manufacturers' guidelines; this lasted about 3-5 min. The following parameters were derived: SV, Q, SBP, diastolic blood pressure (DBP), MAP, RPP, and TPR. MAP is the average 
pressure for the complete period, which is, in effect, the pressure-time integral for the entire cardiac cycle (Smith \& Kampine, 1990). At rest, MAP is estimated as the DBP plus one third of the pulse pressure (difference between systolic and diastolic blood pressures). MAP can also be calculated by multiplication of Q and TPR (Kelman, 1977). TPR is the resistance of the systemic vascular network between aortic root and right atrium. Each parameter was measured on a beatby-beat basis and averaged over each 5-min period. TPR, RPP, and $a-v \mathrm{O}_{2}$ diff were calculated based on data collected via the Portapres and respiratory gases:

$$
\begin{gathered}
\mathrm{TPR}=\mathrm{MAP} \div \mathrm{Q}(\text { Kelman, 1977) } \\
\mathrm{RPP}=\mathrm{HR} \times \mathrm{SBP}(\text { Hui et al., 2000) } \\
a-v \mathrm{O}_{2} \text { diff }=\mathrm{VO}_{2} \div \mathrm{Q}(\text { De Cort et al., 1991) }
\end{gathered}
$$

\section{Respiratory Measurements}

Expired gas was collected using Douglas bags (Plysu Protections Systems Ltd., Milton Keynes, UK) over the last $3 \mathrm{~min}$ of each 15-min bout of exercise. Before gas collection, the Douglas bags were flushed with room air and fully evacuated. Respiratory-gas fractions $\left(\mathrm{O}_{2}\right.$ and $\left.\mathrm{CO}_{2}\right)$ were analyzed (Series 1400 gas analyzer, Servomex Plc., Crowborough, UK), and the volume of expired air was measured (Harvard dry gas meter, Harvard Apparatus Ltd., Edenbridge, UK). The gas analyzer was calibrated using a two-point calibration: $\mathrm{O}_{2}$ and $\mathrm{CO}_{2}$ were zeroed using $100 \%$ nitrogen gas (Linde Gas UK Ltd., West Bromwich, UK); $\mathrm{O}_{2}$ spanned to $20.93 \%$ using room air, and $\mathrm{CO}_{2}$ spanned to $5.99 \%$ using a known gas mixture $(15.09 \%$ $\mathrm{O}_{2}, 5.99 \% \mathrm{CO}_{2}, 78.92 \% \mathrm{~N}$; Linde Gas UK Ltd., West Bromwich, UK). The gas meter was calibrated by pumping room air through in $35-\mathrm{L}$ increments up to 175 L using a 7-L syringe (Model 4900, Hans Rudolph Inc., Kansas City, MO). The known volume was subsequently plotted against the measured volume and a correction factor obtained via regression analysis. This correction factor was then used to correct the collected expired-gas volume. The volume of $\mathrm{VO}_{2}$ was calculated using the Haldane transformation, taking into consideration the additional weight of the Portapres. Data are presented as standard temperature $\left(0^{\circ} \mathrm{C}\right)$ and pressure $(100.3 \mathrm{kPa})$ of dry gas.

\section{Statistical Analysis}

Statistical analysis was performed using Statistical Package for the Social Sciences (SPSS) version 16 (SPSS, Chicago, IL). Correlations and normality checks were performed on all data sets. Due to the strong correlations between Q and SV, SBP and MAP, and DBP and MAP, they could not all be included together in a MANOVA. Therefore, a two-way repeated-measures ANOVA (Time $\times$ Gradient [level or downhill]) was used for Q, TPR, RRP, and MAP. A two-way MANOVA was conducted to compare SV and HR as two dependent variables during downhill and level walking (Time [3] $\times$ Gradient [2)]), as well as SBP and DBP. Pairedsamples $t$ tests were used to analyze $\mathrm{VO}_{2}$, minute ventilation, and $a-v \mathrm{O}_{2}$ diff. All data are presented as $M \pm S D$. Significance was accepted at $p<.05$ and presented with degrees of freedom $(d f)$ and effect size (partial eta-squared, $\left.\eta^{2}\right)$. 


\section{Results}

\section{$\mathrm{VO}_{2}$ and Minute Ventilation}

$\mathrm{VO}_{2}$ during DTW was $9.00 \pm 1.28 \mathrm{ml} \cdot \mathrm{kg}^{-1} \cdot \mathrm{min}^{-1}, 25 \%$ lower, $t(14)=13.65, p<$ .001 , than during LTW $\left(11.94 \pm 1.28 \mathrm{ml} \cdot \mathrm{kg}^{-1} \cdot \mathrm{min}^{-1}\right)$. As a percentage of predicted $\mathrm{VO}_{2 \max }, \mathrm{VO}_{2}$ was $49 \% \pm 27 \%$ during LTW and $37 \% \pm 21 \%$ during DTW. Minute ventilation was $16 \%$ lower, $t(14)=7.24, p<.001$, during DTW $(23.36 \pm 4.56$ vs. $19.52 \pm 4.29 \mathrm{~L} / \mathrm{min})$.

\section{HR, SV, and Q}

Table 1 shows the cardiovascular variables HR, SV, and Q during both LTW and DTW conditions. No violations of the preliminary assumptions for the two-way MANOVA were present in the data. There was a difference between LTW and DTW on the combined dependent variables, $F(2,13)=7.10, p=.008, \eta^{2}=.33$; however there was no effect over time, $F(4,54)=1.66, p>.05, \eta^{2}=.09$, or for the time-gradient interaction, $F(4,54)=1.55, p>.05, \eta^{2}=.20$. When results for the dependent variables were considered separately, SV was statistically different between the two gradients, $F(1,14)=6.80, p=.02, \eta^{2}=.33$. Mean SV during DTW was $12 \%$ lower than during LTW. There were no differences in the overall mean HR between the two conditions, $F(1,14)=3.19, p>.05, \eta^{2}=.19$. Q was found to be $12 \%$ lower during DTW, $F(1,14)=20.70, p<.001, \eta^{2}=.60$.

\section{Blood Pressure Measurements}

SBP and DBP during LTW and DTW are presented in Figure 1. The same preliminary assumptions were made for the SBP and DBP two-way between-groups MANOVA with no violations present. The MANOVA indicated a difference between LTW and DTW on the combined dependent variables SBP and DBP, $F(2$, $13)=51.18, p<.001, \eta^{2}=.89$. Separate consideration of the dependent variables showed only a statistically significant difference for SBP, $F(1,14)=7.28, p=.014$, $\eta^{2}=.36$. The overall mean scores indicated that SBP was lower during DTW than during LTW $(153 \pm 24 \mathrm{mmHg}$ vs. $163 \pm 22 \mathrm{mmHg}$ ). MAP (Figure 2$), F(1,14)=$ $1.24, p>.05, \eta^{2}=.08$, and DBP were not different between conditions, $F(1,14)$ $=0.04, p>.05, \eta^{2}=.003$.

\section{TPR, RPP, and a-v $\mathrm{O}_{2}$ diff}

TPR (Figure 3 ) was not significantly different over the time period during each condition, $F(2,28)=0.78, p>.05, \eta^{2}=.30$, and there was no time-gradient interaction, $F(2,28)=1.33, p>.05, \eta^{2}=.09$. However, TPR was significantly higher, $F(1,14)=5.88, p=.03, \eta^{2}=.30$, during DTW than LTW $(16.21 \pm 6.88$ vs. 14.10 $\pm 4.83 \mathrm{mmHg} \cdot \mathrm{L}^{-1} \cdot \mathrm{min}^{-1}$ ). In addition, RPP was not significantly different over the time period during each condition, $F(2,28)=0.38, p>.05, \eta^{2}=.03$, with no time-gradient interaction, $F(2,28)=0.19, p>.05, \eta^{2}=.01$. However, there was a difference between LTW and DTW, with DTW showing an $8 \%$ lower RPP of $14,828 \pm 2,755$ beats $\cdot \mathrm{min}^{-1} \cdot \mathrm{mmHg}^{-1}$ compared with $16,125 \pm 2,619$ beats $\cdot \mathrm{min}^{-1}$ $\cdot \mathrm{mmHg}^{-1}$ during LTW, $F(1,14)=8.58, p=.01, \eta^{2}=.38$. The $a-v \mathrm{O}_{2}$ diff (Figure 4) 


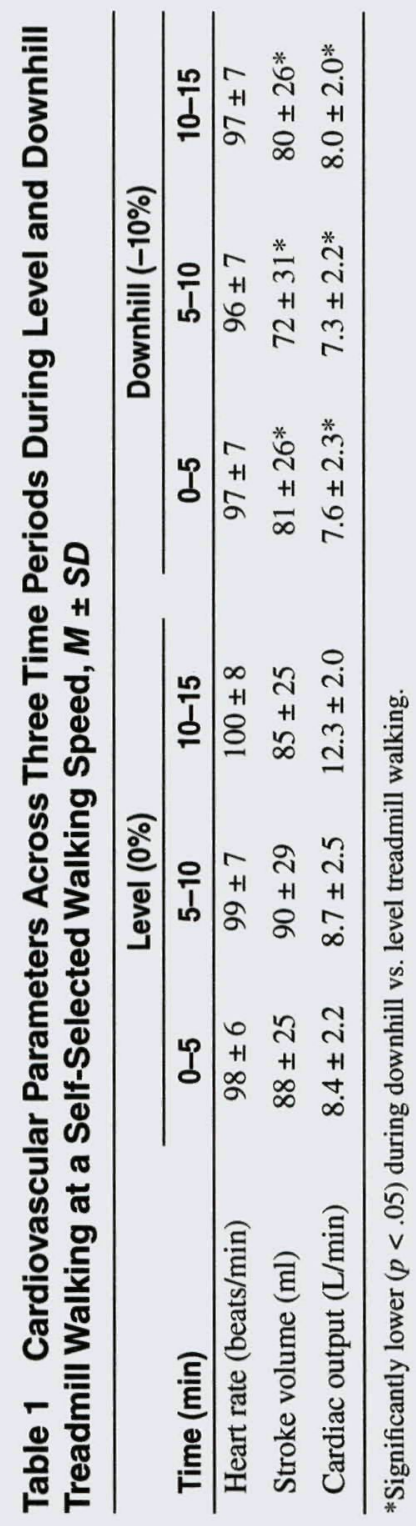



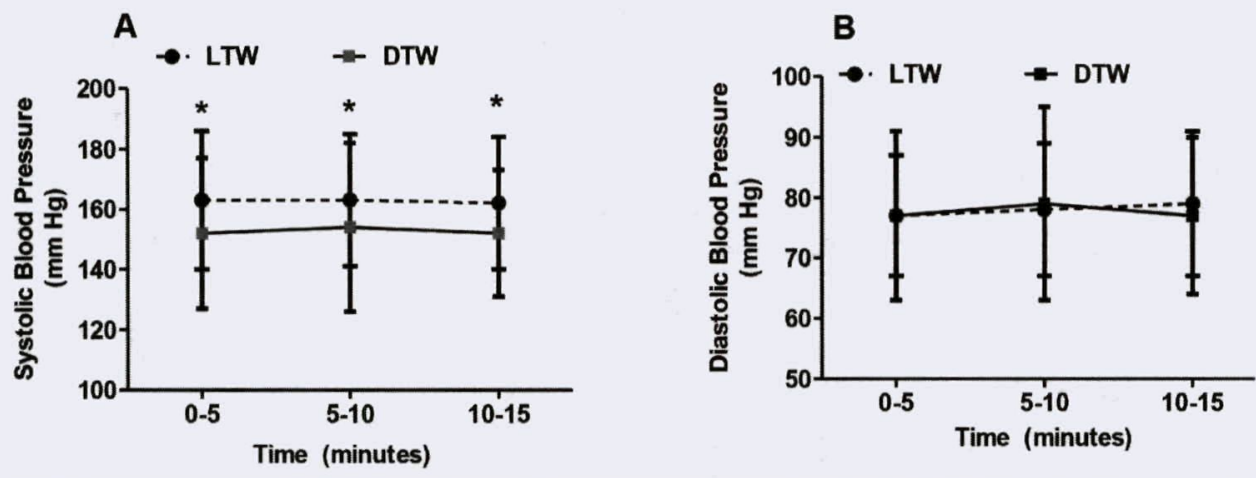

Figure 1 - (A) Systolic and (B) diastolic blood pressure of older adults during level (LTW, 0\%) and downhill (DTW, $-10 \%$ ) treadmill walking at self-selected walking speed, $M \pm S D$. *Significant difference between conditions.

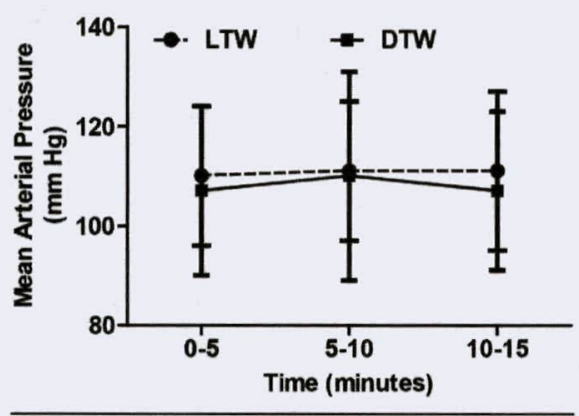

Figure 2 - Mean arterial pressure (DAP + $\{0.333 \times[\mathrm{SAP}-\mathrm{DAP}]\})$ of older adults during level (LTW, 0\%) and downhill (DTW, -10\%) treadmill walking at self-selected walking speed, $M \pm S D$. Note. DAP = diastolic arterial pressure; $\mathrm{SAP}=$ systolic arterial pressure.



Figure 3 - Total peripheral resistance (TPR) of older adults during level (LTW, $0 \%$ ) and downhill (DTW, $-10 \%$ ) treadmill walking at self-selected walking speed, $M \pm S D$. *Significant difference between conditions.

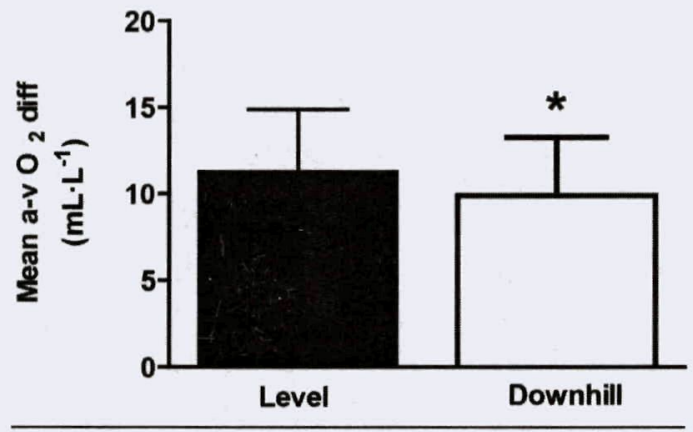

Figure 4 - Arteriovenous oxygen difference $\left(a-v \mathrm{O}_{2}\right.$ diff) of older adults during level $(0 \%)$ and downhill $(-10 \%)$ treadmill walking at self-selected walking speed, $M \pm S D$. *Significant difference between conditions. 
was $11.3 \pm 3.6 \mathrm{ml} / \mathrm{L}$ during LTW; this was reduced by $13 \%$ during DTW to $9.9 \pm$ $3.4 \mathrm{ml} / \mathrm{L}, t(14)=10.35, p<.001$.

\section{Discussion}

The results from the current study generated five major findings: (a) $\mathrm{VO}_{2}$ was reduced during DTW in comparison with LTW, (b) SV and SBP were lower during DTW, (c) the reduced Q during DTW was entirely attributable to the reduced SV as there were no concomitant changes in $\mathrm{HR}$, (d) a diminished $a-v \mathrm{O}_{2}$ diff occurred during DTW, and (e) TPR was higher during DTW than during LTW.

This study recorded $25 \%$ less oxygen required by older adults to walk downhill on a $10 \%$ negative gradient than during level walking at a similar speed. This is in agreement with other studies (Gregor \& Costill, 1973; Navalta et al., 2004; Wanta et al., 1993). In younger and older adults, Navalta et al. (2004) reported a 3-ml . $\mathrm{kg}^{-1} \cdot \mathrm{min}^{-1}$ reduction in $\mathrm{VO}_{2}$ with a walking speed of $4.82 \mathrm{~km} / \mathrm{hr}$ on a $10 \%$ negative gradient, a reduction similar to that reported in the current study.

Robergs et al. (1997) studied the relationship between $\mathrm{VO}_{2}$ and speed. They observed that the slope of the $\mathrm{VO}_{2}$-speed relationship for downhill running at a gradient of $-5.4 \%$ was significantly less than the slope during running on a level surface. Therefore, the magnitude of the increase in $\mathrm{VO}_{2}$ at different running speeds was reduced as the gradient became more negative. Both Robergs et al. and Gregor and Costill (1973) reported decreases in $\mathrm{VO}_{2}$ similar to those found in the current study ( $22 \%$ and $27 \%$, respectively), despite employing less negative gradients (approximately -6\%). In another exercise model that employed eccentric exercise, Bigland-Ritchie and Woods (1976) measured performance on a motorized bicycle ergometer that applied a continuous eccentric load. Eccentric cycling has both concentric and eccentric elements (Steiner et al., 2004). Bigland-Ritchie and Woods reported the oxygen demand for this type of activity to be only one sixth to one seventh of the oxygen demand required for concentric cycling at the same workload. The greater reduction in $\mathrm{VO}_{2}$ during eccentric cycling than during walking or running might be due to differences in the active muscle mass. Downhill treadmill walking employs a larger muscle mass as the exercise is conducted in an erect position, therefore eliciting a greater level of $\mathrm{VO}_{2}$. During downhill walking a high proportion of the work is performed by the quadriceps by stretching of the muscle during the contraction phase as a result of the inertial forces acting on the subject's body mass (Davies \& Barnes, 1972). This type of contraction produces more force than during concentric contractions (Davies \& Barnes, 1972). Therefore, the greater reduction in $\mathrm{VO}_{2}$ during eccentric cycling can be attributed to fewer active muscle fibers contracting to produce a given amount of work in a negative environment.

Few studies have considered the acute cardiovascular responses that occur during eccentric exercise (Navalta et al., 2004; Overend et al., 2000). The ability of the cardiovascular and respiratory systems to deliver oxygen to active tissues is a direct determinant of overall $\mathrm{VO}_{2}$. Systemic $\mathrm{VO}_{2}$ according to the Fick equation is determined by the delivery of oxygen via blood flow and the amount of oxygen extracted by the tissues. Q - the product of SV and HR-in combination with the oxygen extracted by the tissues, determines the rate at which oxygen is 
consumed (Smith \& Kampine, 1990). HR was not significantly different between the level and downhill conditions in the current study, so it can be concluded that the $25 \%$ reduction in $\mathrm{VO}_{2}$ is a direct result of the $\sim 12 \%$ reduction in $\mathrm{SV}$ measured during downhill walking. SV changes to meet exercise demands and is a major determinant of cardiorespiratory endurance capacity. Two mechanisms influence the ventricles' filling capacity: the volume of venous blood returned to the heart (preload) and the distensibility of the ventricles, that is, the capacity that they have to relax and stretch. At a given pressure, these variables determine how much blood enters the ventricles and also contribute toward how much leaves the heart during the contractile phase of the cardiac cycle. Two further mechanisms influence the ventricles' ability to empty: first, ventricular contractility or the inherent capacity of the ventricles to contract, and second, the aortic or pulmonary artery pressure against which the ventricles must contract and overcome to facilitate blood flow (afterload). These variables determine the speed and pressure with which blood is ejected into the systemic circulation. Due to the gravitational force assisting the work being performed during downhill walking, the demand for oxygen delivery is greatly reduced. As a consequence, less blood enters the ventricles, thus decreasing the stretch of the ventricular walls and the contractile force. Reductions in SV are therefore either the result of a diminished ejection fraction, which results in more blood remaining in the left ventricle after systole (Poliner et al., 1980), or a reduced volume of blood in the left ventricle for it to eject. In the current study, HR was not significantly different between the two conditions. Therefore, the filling time for the left ventricle and consequently the end diastolic volume remained consistent. Consequently, a reduced SV in response to downhill walking would be the result of a lower required contractile force increasing the end-systolic volume for the left ventricle.

Although eccentric movements require less muscle activation, TPR was increased during downhill walking, possibly indicating that venous pressure increased (although this was not measured directly), assisting the return of deoxygenated blood to the heart. During exercise, small resistance vessels exhibit a blunted vasodilatory capacity, contributing to an increased TPR (Hambrecht et al., 2000), so it is possible that this response is increased further during downhill walking. More valid methods were used by Hambrecht et al. to assess Q, blood pressure, and TPR (thermodilution catheter). Such methods could be used to assess endothelial changes in skeletal muscle of the lower limbs. This could allow comparison of such changes during downhill and level walking. The formula used for calculating TPR expects an inverse correlation between SV and TPR, in the absence of major changes in blood pressure and HR (Hambrecht et al., 2000). The lack of change in HR response between level walking and downhill walking is in agreement with the findings of Navalta et al. (2004), indicating that SV was responsible for the change in $\mathrm{Q}$, reducing the delivery of oxygen to working muscles and therefore the reduced $\mathrm{VO}_{2}$. The other half of the Fick equation $\left(a-v \mathrm{O}_{2}\right.$ diff $)$ accounts for the remaining reduction seen in $\mathrm{VO}_{2}$. The metabolic demands of downhill walking are significantly lower than during level walking. As a result, the working muscles demand and consume less oxygen. Therefore, the $a-v \mathrm{O}_{2}$ diff is less during downhill walking, as less oxygen is being used by the muscles (Wanta et al., 1993).

RPP, an index of cardiovascular strain (Hui et al., 2000), was lower during downhill treadmill walking, indicating further the lower cardiovascular strain in 
comparison with level treadmill walking. This indirectly illustrates that the heart is working less, requiring a lower myocardial $\mathrm{VO}_{2}$ during downhill walking. Navalta et al. (2004) indicate similar changes in RPP between level and downhill treadmill walking, with a $-10 \%$ gradient being approximately $10 \%$ lower. They also report a $39 \%$ increase in RPP of older adults from rest to walking. The current participants had a $32 \%$ increase from resting values; however, their mean resting values for RPP were much higher ( 8 participants were $>10,000$ ) than those in Navalta et al., a suggestive risk factor for cardiovascular disease. Therefore, an activity such as this that elicits a lower cardiovascular strain on individuals with an increased risk of cardiovascular disease and a lower aerobic capacity should allow safe participation.

There are a number of limitations of the current study. An overall decrease in $\mathrm{VO}_{2}$ during downhill walking was reported, with two underlying causes, reduced SV and $a-v \mathrm{O}_{2}$ diff, although the latter was not measured directly. Therefore, invasive techniques could be used to directly measure $a-v \mathrm{O}_{2}$ diff and TPR to confirm the conclusions of the current study. In addition, the small participant numbers may prove to be a limitation of this study, although medium-large effect sizes were calculated throughout.

In summary, healthy older adults require $25 \%$ less oxygen during downhill walking than level walking at the same self-selected walking speed. This may be the result of the fact that fewer active muscle fibers are required to produce the amount of negative work. The reduction in oxygen demand is attributable to two main mechanisms: a $12 \%$ reduction in stroke volume and a $12 \%$ reduction in $a-v$ $\mathrm{O}_{2}$ diff. The reduced stroke volume not only causes a decline in cardiac output but also significantly reduces systolic blood pressure, as less pressure is being imparted on the systemic circulation. The data also indicate that downhill walking at a self-selected walking speed places a significantly reduced cardiac load on the individual compared with level walking. Thus, the cardiovascular demands of downhill walking make it a safe alternative form of exercise. Future work is warranted on whether downhill walking is suitable for higher risk (e.g., peripheral arterial disease) and older populations.

\section{References}

American College of Sports Medicine, Chodzko-Zajko, W.J., Proctor, D.N., Fiatarone Singh, M.A., Minson, C.T., Nigg, C.R., . . . Skinner, J.S. (2009). American College of Sports Medicine position stand. Exercise and physical activity for older adults. Medicine and Science in Sports and Exercise, 41(7), 1510-1530. PubMed doi:10.1249/ MSS.0b013e3181a0c95c

Bassett, D.R., \& Howley, T.E. (2000). Limiting factors for maximum oxygen uptake and determinants of endurance performance. Medicine and Science in Sports and Exercise, 32(1), 70-84. PubMed doi:10.1097/00005768-200001000-00012

Berne, R.M., \& Levy, M.N. (1981). Cardiovascular physiology (4th ed.). St. Louis, MO: C.V. Mosby.

Bigland-Ritchie, B., \& Woods, J.J. (1976). Integrated electromyogram and oxygen uptake during positive and negative work. The Journal of Physiology, 260(2), 267-277. Retrieved from http://jp.physoc.org. PubMed

Davies, C.T., \& Barnes, C.A. (1972). Negative (eccentric) work. II. Physiological responses of walking uphill and downhill on a motor driven treadmill. Ergonomics, 15(2), 121-131. PubMed doi:10.1080/00140137208924416 
De Cort, S.C., Innes, J.A., Barstow, T.J., \& Guz, A. (1991). Cardiac output, oxygen consumption and arteriovenous oxygen difference following a sudden rise in exercise level in humans. The Journal of Physiology, 441, 501-512 Retrieved from http://jp.physoc. org. PubMed

Eckert, S., \& Horstkotte, D. (2002). Comparison of Portapres non-invasive blood pressure measurement in the finger with intra-aortic pressure measurement during incremental bicycle exercise. Blood Pressure Monitoring, 7(3), 179-183. PubMed doi:10.1097/00126097-200206000-00006

Gault, M.L., Clements, R.E., \& Willems, E.T. (2009). Effect of wearing the Cosmed K4b ${ }^{2}$ metabolic system on 1 mile walking performance in older adults. Journal of Human Kinetics, 21, 41-48. doi:10.2478/v10078-09-0005-6

Goodman, J.M., Liu, P.P., \& Green, H.J. (2005). Left ventricular adaptations following short term endurance training. Journal of Applied Physiology, 98(2), 454-460. PubMed doi:10.1152/japplphysiol.00258.2004

Gregor, R.J., \& Costill, D.L. (1973). A comparison of the energy expenditure during positive and negative grade running. Journal of Sports Medicine and Physical Fitness, 13(4), 248-252. PubMed

Hambrecht, R., Gielen, S., Linke, A., Fiehn, E., Yu, J., Walther, C., . . Schuler, G. (2000). Effects of exercise training on left ventricular function and peripheral resistance in patients with chronic heart failure: A randomized trial. Journal of the American Medical Association, 283(23), 3095-3101. PubMed doi:10.1001/jama.283.23.3095

Hui, S.C., Jackson, A.S., \& Wier, L.T. (2000). Development of normative values for resting and exercise rate pressure product. Medicine and Science in Sports and Exercise 32(8), 1520-1527. doi:oclc/35792421

Kelman, G.R. (1977). Applied cardiovascular physiology (2nd ed.). London, UK: Butterworth \& Co.

Kline, G.M., Porcari, J.P., Hintermeister, R., Freedson, P.S., Ward, A., McCarron, R.F., . . Rippe, J.M. (1987). Estimation of $\mathrm{VO}_{2 \max }$ from a one-mile track walk, gender, age, and body weight. Medicine and Science in Sports and Exercise, 19(3), 253-259 Retrieved from http://journals.lww.com/acsm-msse/. PubMed doi:10.1249/00005768198706000-00012

Mbada, C.E., Akinwande, O.A., Babalola, J.F., Seyi-Adeyemo, O.R., \& Odejide, A.S. (2007). Gender differences in cardiovascular response to upper extremities isometric exercises in normotensive subjects. Nigerian Journal of Medical Rehabilitation, 12, 30-34 Retrieved from http://www.mrtbjournal.org/index.php/njmr/issue/view/3

Navalta, J.W., Sedlock, D.A., \& Park, K.S. (2004). Physiological responses to downhill walking in older and younger individuals. Journal of Exercise Physiology-online, 7(6), 45-51 Retrieved from http://www.asep.org/journals/JEPonline

Overend, T.J., Versteegh, T.H., Thompson, E., Birmingham, T.B., \& Vandervoort, A.A. (2000). Cardiovascular stress associated with concentric and eccentric isokinetic exercise in young and older adults. The Journals of Gerontology. Series A, Biological Sciences and Medical Sciences, 55(4), B177-B182. PubMed doi:10.1093/gerona/55.4.B177

Parati, G., Casadei, R., Groppelli, A., Di Rienzo, M., \& Mancia, G. (1989). Comparison of finger and intra-arterial blood pressure monitoring at rest and during laboratory testing. Hypertension, 13(6 Pt. 1), 647-655. PubMed doi:10.1161/01.HYP.13.6.647

Peñáz, J. (1973). Photoelectric measurement of blood pressure, volume and flow in the finger. In A. Albert, W. Vogt, \& W. Hellig (eds.), Digest of the 10th International Conference on Medical and Biological Engineering (p. 104). Dresden, Germany: International Federation for Medical and Biological Engineering.

Pitt, M.S., Marshall, P., Diesch, J.P., \& Hainsworth, R. (2004). Cardiac output by Portapres. Clinical Science, 106, 407-412. PubMed doi:10.1042/CS20030279 
Pivarnik, J.M., \& Sherman, N.W. (1990). Responses of aerobically fit men and women to uphill/downhill walking and slow jogging. Medicine and Science in Sports and Exercise, 22(1), 127-130. PubMed doi:10.1249/00005768-199002000-00020

Poliner, L.R., Dehmer, G.J., Lewis, S.E., Parkey, R.W., Blomqvist, C.G., \& Willerson, J.T. (1980). Left ventricular performance in normal subjects: A comparison of the responses to exercise in the upright and supine position. Circulation, 62(3), 528-534. PubMed doi:10.1161/01.CIR.62.3.528

Robergs, R.A., Wagner, D.R., \& Skemp, K.M. (1997). Oxygen consumption and energy expenditure of level versus downhill running. Journal of Sports Medicine and Physical Fitness, 37(3), 168-174. PubMed

Roig, M., Shadgan, B., \& Reid, W.D. (2008). Eccentric exercise in patients with chronic health conditions: A systematic review. Physiotherapy Canada. Physiotherapie Canada, 60(2), 146-160. PubMed doi:10.3138/physio.60.2.146

Rothe, C.F. (1986). Physiology of venous return: An unappreciated boost to the heart. Archives of Internal Medicine, 146(5), 977-982. PubMed doi:10.1001/ archinte.1986.00360170223028

Smith, J.J., \& Kampine, J.P. (1990). Circulatory physiology: The essentials (3rd ed.). Baltimore, MD: Williams \& Wilkins.

Steiner, R., Meyer, K., Lippuner, K., Schmid, J.P., Saner, H., \& Hoppeler, H. (2004). Eccentric endurance training in subjects with coronary artery disease: A novel exercise paradigm in cardiac rehabilitation? European Journal of Applied Physiology, 91(5-6), 572-578. PubMed doi:10.1007/s00421-003-1000-6

Wanta, D.M., Nagle, F.J., \& Webb, P. (1993). Metabolic response to graded downhill walking. Medicine and Science in Sports and Exercise, 25(1), 159-162. PubMed doi:10.1249/00005768-199301000-00022

Wass, E., Taylor, N.F., \& Matsas, A. (2005). Familiarisation to treadmill walking in unimpaired older people. Gait \& Posture, 21(1), 72-79. PubMed doi:10.1016/j.gaitpost.2004.01.003

Wesseling, K.H., de Wit, B., Settels, J.J., \& Klawer, W.H. (1992). On the indirect registration of finger blood pressure after Penáz. Funktionelle Biology \& Medizin, 1, 245-250. 
Copyright of Journal of Aging \& Physical Activity is the property of Human Kinetics Publishers, Inc. and its content may not be copied or emailed to multiple sites or posted to a listserv without the copyright holder's express written permission. However, users may print, download, or email articles for individual use. 